\title{
ECO-REGIÓN EJE CAFETERO: UNA EXPERIENCIA DE DESARROLLO REGIONAL EN COLOMBIA.
}

\author{
Oscar Arango Gaviria ${ }^{1}$ \\ Comité Técnico Alma Mater. \\ Universidad Tecnológica de Pereira.
}

Remisión artículo: 26-03-2008
Remisión definitiva: 16-04-2008.

Palabras Clave: Ecorregión, participación ciudadana, dinámicas urbano regionales.

Resumen: Con la expedición de la Ley 388 de 1997, se inicia un nuevo proceso de planificación y desarrollo territorial en Colombia. Los preceptos contemplados en dicha Ley, aunados a procesos político-institucionales en la Eco-región Eje Cafetero, han permitido efectuar propuestas interesantes para su desarrollo regional. En este contexto, el artículo realiza una síntesis de algunos de los elementos que han ayudado a la construcción social, cultural y política de la Eco-región Eje Cafetero Colombiano. Asimismo, se puntualiza la diferenciación entre regiones y eco-regiones; se describe la ubicación y la delimitación territorial de la Ecorregión; se llama la atención sobre la dinámica urbano-regional haciendo énfasis en los cambios poblacionales 1993-2005, subrayando los procesos subregionales y de metropolización, acorde con el marco general de la Ley 388 de 1997. También se describen las dinámicas socioeconómicas y ambientales; se analiza el estado de las finanzas públicas, y el entramado institucional y político administrativo, y por separado se trata el tema del conflicto armado. Finalmente, se describen los principales componentes de las agendas para el desarrollo propuestas en esta Eco-región.

\section{Regiones y Eco-regiones.}

Antes de abordar las eco-regiones como punto central del artículo, iniciaremos con una breve ilustración del concepto región, como aspecto de partida en la argumentación relacionada con las eco-regiones.

En la teoría relacionada con el desarrollo regional, se ha destacado que las Regiones son "realidades geográficas, sociales, históricas, y económicas, a veces étnicas, que tienen derecho a un espacio en la organización político-institucional del país" (Castro, 2002, pág. 49).

Según Castro (2002), son dos los elementos que configuran una Región: por una parte, "la identidad social y cultural que crea y desarrolla lazos de pertenencia y solidaridad tan fuertes que la comunidad que los posee se siente y es distinta de las demás comunidades con las que convive en la misma Nación o Estado", y por la otra, "la comunidad de que se trate tiene su asiento en un área territorial determinada -o determinable- que también reúne características que la hacen particular y distinta. A veces, inclusive, se trata también de una Eco-región" ${ }^{2}$. Este es el caso del cual nos ocupamos en adelante para describir la dinámica de la Eco-región Eje Cafetero.

\footnotetext{
${ }^{1}$ Persona de contacto: Oscar Arango Gaviria, correo electrónico: oscar.arango@almamater.edu.co.

${ }^{2}$ Para ampliar ver: Castro, Jaime. La cuestión territorial. Bogotá: Oveja Negra, 2002.
} 
Aunque las eco-regiones no están definidas como tales en la Constitución de Colombia, ni en su normatividad vigente, ello no significa que no existan en la realidad. En nuestro país no pocas de las reflexiones que se hacen sobre la necesidad de un reordenamiento territorial pasan, de una u otra manera, por la configuración socio cultural y político institucional de estos territorios.

De hecho, hacia 1998 el entonces Ministerio del Medio Ambiente, emprendió programas de conservación y restauración de eco-regiones que por su valor natural o su importancia para la actividad económica y el bienestar de la población, fuesen consideradas estratégicas ${ }^{3}$ y de cuya oferta de bienes y servicios ambientales dependiera en gran medida la dinamización, sostenibilidad del desarrollo regional y la viabilidad económico-social.

En la política denominada Proyecto Colectivo Ambiental, los seis criterios que dicho Ministerio reconoce para la identificación de las Eco-regiones son ${ }^{4}$ :

- Presencia de unidades ecológicas prioritarias para la retención y regulación de agua;

- Presencia de ecosistemas estratégicos;

- Territorio compartido por más de dos entes territoriales y que corresponde a jurisdicción de más de dos Corporaciones Autónomas Regionales;

- Posibilidad de articular territorialmente acciones relacionadas con varias áreas temáticas del Proyecto Colectivo Ambiental;

- Posibilidad de vincular la oferta natural a la solución de conflictos y al bienestar de la población;

- Posibilidad de articular diversas fuentes y recursos económicos.

A través del proceso de construcción de las Eco-regiones los actores sociales e institucionales deben participar en la identificación de prioridades ambientales y plantear alternativas de solución que posteriormente se concretan en procesos de gestión articulada y colectiva.

En estas Eco-regiones se encuentran ecosistemas, cuya funcionalidad estratégica se explica bajo la premisa de mantener equilibrios ecológicos básicos (regulación hídrica y climática), el abastecimiento de agua, energía y alimentos, y la prevención de riesgos y desastres naturales. En ellas se sitúan páramos, humedales, bosques protectores, áreas protegidas, microcuencas abastecedoras de acueductos, riego o receptoras de vertimientos líquidos, áreas degradadas que presentan situaciones de insostenibilidad productiva, áreas frágiles y corredores biológicos, entre otros.

Por otra parte, las Eco-regiones estratégicas se entienden como "laboratorios e instrumentos pedagógicos de gestión ambiental colectiva y articulada, y cumplen un papel fundamental para la concreción de la política, ya que permiten impulsar procesos de gestión ambiental colectiva en áreas prioritarias y contribuyen a dinamizar el Sistema Nacional Ambiental. Con esto se pretende potenciar la capacidad para enfrentar los problemas ambientales, generando condiciones para dar coherencia a las distintas acciones que se realicen en estos territorios en cumplimiento de la política" (MAVDT, 2003).

En nuestro caso particular, la Ecorregión Eje Cafetero tiene su origen en las políticas del Ministerio de Ambiente a fines de los años 90 y que se refuerza con el proceso de

\footnotetext{
${ }^{3}$ Entre ellas se citan los casos de las Eco-regiones del Amazonas, del Macizo colombiana, de La Mojana o del Eje Cafetero.

4 Ministerio de Ambiente Vivienda y Desarrollo Territorial (MAVDT). Recuperado 23 de mayo, 2007, de http://web.minambiente.gov.co/ecorre/intro/intro3.htm.
} 
reconstrucción que se desarrolló en los 28 municipios afectados por el terremoto de $1999^{5}$. En cierta forma, esta es una Ecorregión que, desde la tragedia, ha vuelto a retomar importancia en un momento en que debió enfrentar no sólo los impactos del desastre, sino la mayor crisis económica y social conocida en su historia.

\section{Ubicación y delimitación}

La del Eje Cafetero es una Eco-región conformada por tres grandes corredores ambientales que actúan como ejes estructurantes de la misma:

a. El corredor ambiental de la cordillera Central, que tiene su origen en el páramo de Sonsón en el suroriente de Antioquia en límites con Caldas, continuando con los páramos de San Félix en Caldas y el Parque Nacional Natural los Nevados compartido por Caldas, Risaralda, Quindío y Tolima, extendiéndose hacia el sur por el páramo de Chilí en el municipio de Génova (Quindío) y culminando en el Parque Nacional Natural las Hermosas en el Valle del Cauca.

b. El corredor ambiental de la cordillera Occidental, que inicia en el Parque Nacional Natural Las Orquídeas en el suroccidente de Antioquia, continuando con la cuchilla de San Juan, Parque Nacional Natural Tatamá y serranía de Los Paraguas en Risaralda y norte del Valle del Cauca, culminando con el Parque Nacional Los Farallones en el Valle.

c. El corredor ambiental del río Cauca, gran eje fluvial y asiento de poblaciones gracias a la fertilidad de sus suelos. Las principales cuencas hidrográficas del Eje Cafetero (ríos La Vieja, Risaralda, Chinchiná, entre otros) son tributarias del río Cauca.

Entre otras, las condiciones hidrológicas, de suelo, pendientes, altitud, y de clima, han hecho de este un territorio de gran aptitud para la producción cafetera. De hecho, gran parte de su historia económico-social y política, lo mismo que sus propias posibilidades de desarrollo han estado y están asociadas a la producción y comercialización del grano.

La estructura territorial del Eje Cafetero también implica complejas relaciones de vecindad, conectividad y continuidad con el Chocó biogeográfico en el occidente; el Valle del Magdalena en el oriente; Antioquia en el norte, y Valle del Cauca y Macizo Colombiano en el sur.

La Ecorregión está situada en el centro del triángulo Bogotá-Cali-Medellín donde habita el $58 \%$ de la población total del país, se produce el $76 \%$ del producto interno bruto, se realiza el $75 \%$ del comercio y se ofrece el $73 \%$ de los servicios generales. Al Eje Cafetero le cruzan ejes de desarrollo geoeconómico, como el conformado por Buenaventura-Bogotá-Caracas, integrador del comercio entre el Atlántico y el Pacífico; a su interior se desarrollan proyectos de gran trascendencia para el país como el puerto multimodal de La Dorada, el aeropuerto de Palestina, el puerto seco de La Tebaida, la terminación de la troncal del Cauca, la rehabilitación del ferrocarril de Occidente en 500 Km. (Buenaventura-La Felisa) o el túnel de La Línea.

\section{La dinámica urbano-regional}

La Eco-región está integrada por 92 municipios de los departamentos de Caldas, Risaralda, Quindío, norte del Valle y noroccidente del Tolima, donde viven aproximadamente 3.9 millones de habitantes. La participación en la población nacional tiende a decrecer: en 1973 era el $11,6 \%$ y en el 2005 fue de 9\%. En el período intercensal 1993-2005 se presentó un

\footnotetext{
${ }^{5}$ El 25 de enero de 1999, en la ciudad de Armenia ocurrió un terremoto de 6,2 grados en la escala de Richter, el cual dejó, según los datos de la Dirección de Atención y Prevención de Desastres, 4.795 heridos y 1.171 muertos.
} 
decrecimiento poblacional absoluto en 50 de los 92 municipios.

De esta manera, los cambios intercensales 1993-2005 son poco menos que preocupantes. En Caldas 18 de los 27 municipios disminuyeron población en términos absolutos y el departamento redujo su población de 925 mil a 898 mil habitantes. En conjunto, la población rural continuó disminuyendo en términos absolutos y relativos. Esta información, sumada a la de los 12 municipios que solo crecieron en menos de mil habitantes, muestra un agudo problema de despoblamiento que, sin duda, refleja neurálgicos problemas en su estructura productiva y que trae consigo graves dificultades para garantizar la viabilidad político institucional de estas municipalidades.

\subsection{Jerarquización del sistema de ciudades}

Las condiciones geográficas y ambientales que caracterizan esta Ecorregión han determinado distintos modelos de ocupación y poblamiento, claramente diferenciados entre ellos, por sus niveles de integración, su actividad económica y sus dinámicas propias (Ver figura 1).

En la jerarquización funcional de la red urbana nacional, se ordenan los centros urbanos de acuerdo a los servicios ${ }^{6}$ que cada uno dispone para sí, y para la demanda localizada en su área de influencia. Desde este punto de vista, se pueden observar las siguientes dinámicas:

Por su tamaño poblacional. Las ciudades capitales: Ibagué, Pereira, Manizales y Armenia, concentran la mayoría de la población urbana y tienen más de 250 mil habitantes cada una, ubicándose en la primera jerarquía. Armenia se destaca por la mayor tasa de urbanización (97\%), mientras que Pereira tiene $81 \%$, pero es la segunda ciudad de Colombia con mayor número de pobladores rurales (70 mil). En la segunda jerarquía se encuentran los municipios de Tulúa, Cartago y Dosquebradas con una población entre 100 mil y 200 mil habitantes que concentran el $8 \%$ de la población total de los 92 municipios. Entre 50 mil y 100 mil habitantes se encuentran Chinchiná, Riosucio, La Dorada, Calarcá y Santa Rosa, que también representan el $8 \%$ del total.

\footnotetext{
${ }^{6}$ Financieros, aeropuertos, hospitales, museos, estadios, entre otros.
} 


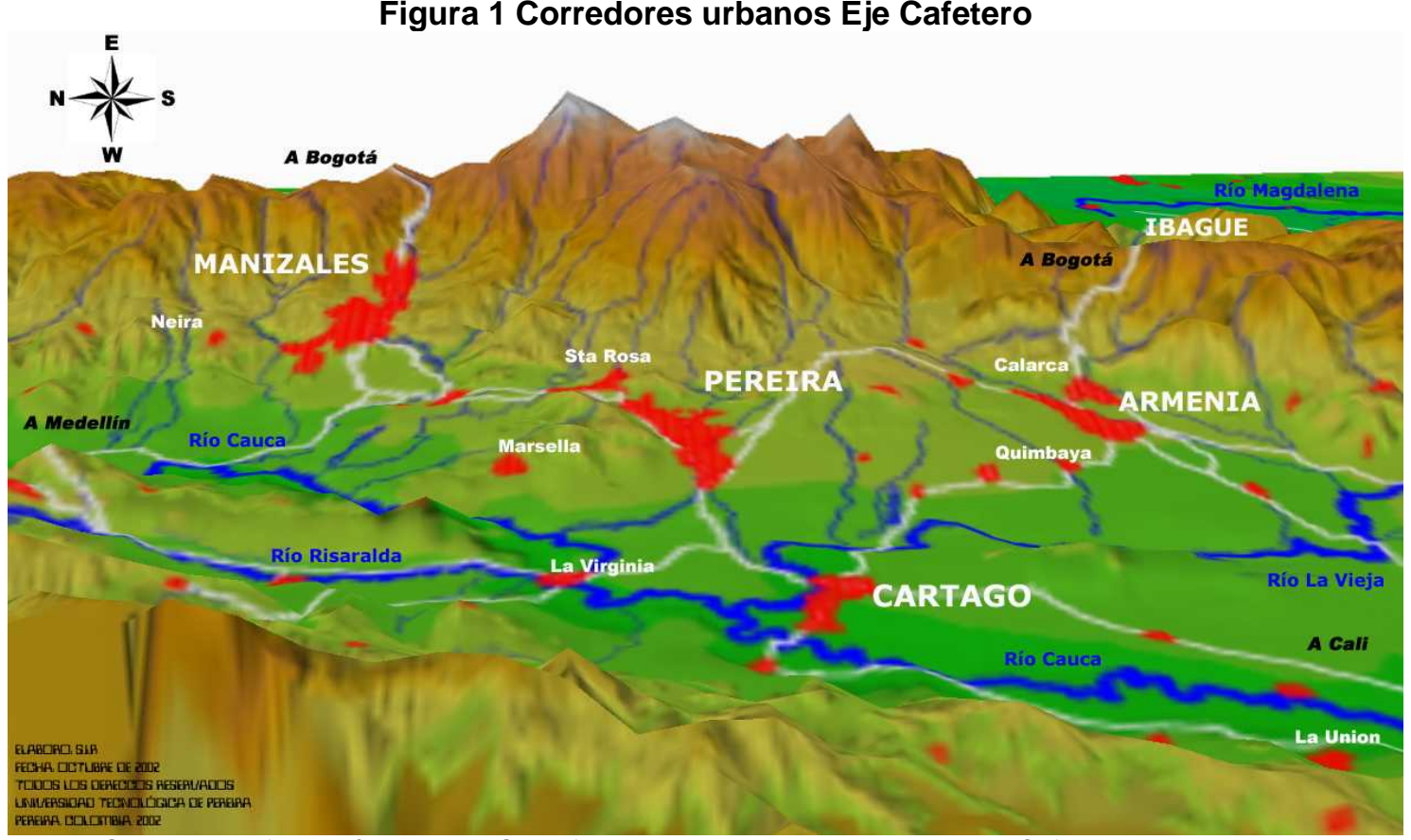

Fuente: Sistema de Información Regional SIR Infraestructura de Datos Espaciales Eje Cafetero

Procesos de metropolización ${ }^{7}$. Al interior del corredor urbano-regional del Eje Cafetero se evidencia otra escala de urbanización, con tres procesos de diverso grado de avance:

- La zona metropolizada de Caldas: compuesta por la subregión centro-sur, la cual está conformada por los municipios de Manizales, Neira, Palestina Chinchiná y Villa María.

- La zona metropolizada del Quindío: integrada por los municipios de Armenia, Circasia, Calarcá, La Tebaida y Montenegro.

- La zona metropolizada de Risaralda y Valle: de la cual hacen parte el Área Metropolitana Pereira, Dosquebradas y La Virginia, y sus municipios de influencia más directa, esto es, Alcalá, Cartago y Ulloa (en el Valle), y Santa Rosa de Cabal y Marsella, en Risaralda.

En conjunto este corredor urbano-regional posee una población aproximada de 1.9 millones de habitantes, que constituyen casi la mitad del total de la Ecorregión, y una población urbana de 1.6 millones de habitantes. Sobresale el nivel de concentración urbana de esta población (88\%). Para el período 1993-2005 la tasa de crecimiento anual de estas zonas metropolizadas fue del $1,74 \%$.

Ahora bien, las distancias entre los municipios y sus respectivas ciudades capitales son relativamente cortas, si se las compara con otras regiones del país. En la tabla 3 se puede observar cómo entre algunos de los puntos extremos existe una distancia no superior a 325 $\mathrm{Km}$, pero es igualmente claro que en la gran mayoría de los casos, las distancias no superan los $100 \mathrm{~km}$ y que los nuevos sistemas viales han acortado significativamente el tiempo promedio de los recorridos.

Esta última circunstancia coadyuva para el aceleramiento de los procesos de conurbación que se presentan alrededor de las ciudades de Armenia, Manizales y Pereira.

\footnotetext{
${ }^{7}$ Se entiende por metropolización, un conjunto de dos o más centros urbanos integrados a partir de un núcleo principal, vinculados entre sí por estrechas relaciones de orden físico, económico y social, y que funcionan como un solo núcleo.
} 
Tabla 1 Eco-región eje cafetero. Jerarquización del sistema de ciudades, según tamaño poblacional 2005

\begin{tabular}{|c|c|c|c|c|c|c|c|}
\hline \multicolumn{2}{|c|}{ Rangos (Habitantes.) } & \multicolumn{3}{|c|}{$\begin{array}{c}\text { Por su tamaño poblacional } \\
\text { total }\end{array}$} & \multicolumn{3}{|c|}{$\begin{array}{c}\text { Por su tamaño poblacional } \\
\text { urbano }\end{array}$} \\
\hline Y Jerarquías () & & $\begin{array}{l}\text { No. de } \\
\text { Municipios. }\end{array}$ & $\begin{array}{c}\text { No. de } \\
\text { Habitantes. }\end{array}$ & $\begin{array}{c}\text { \% Sobre la } \\
\text { población } \\
\text { total }\end{array}$ & $\begin{array}{l}\text { No. de } \\
\text { Municipios. }\end{array}$ & $\begin{array}{c}\text { No. de } \\
\text { Habitantes. }\end{array}$ & $\begin{array}{c}\text { \% sobre la } \\
\text { población. } \\
\text { urbana } \\
\text { total }\end{array}$ \\
\hline $30.001-50.000$ & $(4)$ & 16 & 580.122 & 14,99 & 6 & 210307 & 7,18 \\
\hline $50.001-100.000$ & (3) & 5 & 324.659 & 8,39 & 3 & 178030 & 6,08 \\
\hline $100001-200.000$ & $(2)$ & 3 & 491.407 & 12,70 & 3 & 452767 & 15,46 \\
\hline
\end{tabular}

Fuente: Elaboración propia con base en DANE. Censo nacional de población, viviendas y unidades económicas, 2005

Tabla 2 Eje cafetero. Población en zonas con procesos de metropolización

\begin{tabular}{lrrr}
\hline Zonas metropolizadas & Urbana & Rural & Total \\
De Caldas & 454878 & 71089 & 525967 \\
De Quindío & 412124 & 43367 & 455491 \\
De Risaralda y Valle & 773550 & 120127 & 893677 \\
Total & 1640552 & 234583 & 1875135 \\
Población de la Ecorregión & 2928021 & 941489 & 3869510 \\
\% sobre la Ecorregión & 56,03 & 24,92 & 48,46 \\
\hline Fuente: Elaboración propia con base en información DANE & &
\end{tabular}

Tabla 3 Eco-región eje cafetero. Algunas distancias intermunicipales

\begin{tabular}{|c|c|c|c|c|c|c|c|c|}
\hline Ciudad & Tulua & Cartago & Pereira & Manizales & Armenia & Cajamarca & Ibagué & La Dorada \\
\hline Tulua & & 92 & 108 & 153 & 101 & 141 & 170 & 325 \\
\hline Cartago & 92 & & 16 & 61 & 43 & 94 & 123 & 236 \\
\hline Pereira & 108 & 16 & & 45 & 35 & 86 & 115 & 217 \\
\hline Manizales & 153 & 61 & 45 & & 80 & 131 & 160 & 172 \\
\hline Armenia & 101 & 43 & 35 & 80 & & 51 & 80 & 252 \\
\hline Cajamarca & 141 & 94 & 86 & 131 & 51 & & 29 & 188 \\
\hline Ibagué & 170 & 123 & 115 & 160 & 80 & 29 & & 159 \\
\hline La Dorada & 325 & 236 & 217 & 172 & 252 & 108 & 159 & \\
\hline
\end{tabular}

Fuente: Instituto Nacional de Vías INVIAS.

\section{Una lectura socio económica}

Es cierto que los servicios públicos domiciliarios, así como los de educación y salud tienen una cobertura cada vez mayor y que en algunos casos ya se aproxima al $100 \%$, pero no sucede igual con la calidad de prestación de los mismos. 
El Informe de Desarrollo Humano (PNUD, 2003) concluyó que la región, prácticamente perdió la década 1993-2002 y no existen razones para creer que se esté transformando estructuralmente esta tendencia. Hace falta, por lo tanto, agrupar las voluntades políticoinstitucionales para generar una política pública que otorgue prioridad al cumplimiento en cada municipio de las metas del milenio.

Los municipios de esta Eco-región comparten como otra de sus características la de contar con una tradición en el cultivo y comercialización de café. Su historia está atada a los desarrollos y altibajos de la producción cafetera. Al lado de este cultivo han ido apareciendo desarrollos agroindustriales y cadenas productivas de relativa importancia (frutícola, avícola, forestal, entre otros). Las nuevas perspectivas de la seguridad alimentaria y sus estrechas relaciones con la economía campesina comienzan a dar sus frutos en varios municipios.

La actividad industrial y exportadora se ha visto seriamente afectada en los últimos años como producto de la revaluación y de los nuevos arreglos institucionales del mercado mundial. El impacto sobre la industria de las confecciones, sobre las remesas ${ }^{8}$ y sobre los ingresos por exportación de café ha sido particularmente grave.

Aún con ciertas limitaciones, se empieza a contar con una nueva infraestructura y políticas públicas que promueven la comercialización de productos diferentes al café. Sin embargo, es evidente la dependencia que aún se tiene de la economía cafetera en la gran mayoría de estos 92 municipios. Se cuenta con poco valor agregado en la producción y la crisis agropecuaria no se enfrenta con políticas estructurales.

Poco a poco la región se ha ido posicionando como una importante prestadora de servicios, en especial turísticos. Si bien este servicio ha progresado significativamente en la Eco-región, es claro que hacen falta acuerdos estratégicos para dotarlo de un plan que articule esfuerzos, recursos y voluntades, y lo sitúe en condiciones de ofrecer paquetes más integrales.

Por su parte, la actividad comercial cobra cada vez mayor peso específico en la composición del producto de ciudades como Pereira, Ibagué o Manizales. En la última década se han asentado en este territorio no menos de 10 grandes empresas comerciales (nacionales y extranjeras).

Los observadores también resaltan una baja articulación entre los sectores primario, secundario y terciario de la economía regional, una alta vulnerabilidad por la internacionalización de la economía y una baja educación aplicada a ciencia y tecnología.

Aún más, se ha hecho notar que los procesos económicos no se apoyan realmente en las bondades de la plataforma natural y que, por el contrario, son cada vez más frecuentes los conflictos de uso. Lo dicho es preocupante si se atienden las características ambientales de la Ecorregión.

En 85 de los 92 municipios se presenta una alta dependencia en el sector agrícola y estatal, y una falta de generación de nuevas fuentes de empleo. Los problemas del desempleo abierto y del subempleo siguen siendo un rasgo distintivo que afecta el $70 \%$ de la población económicamente activa ${ }^{9}$. De igual manera, es evidente que la mayoría de los municipios

\footnotetext{
${ }^{8}$ La Eco-región tiene la mayor proporción, a nivel nacional, de migrantes en el exterior, es por esto que las fluctuaciones de la tasa de cambio de la moneda, repercute seriamente en la estructura socio-económica de miles de familias de la Ecorregión, debido a la variación del poder adquisitivo que tienen las remesas enviadas desde el exterior.

${ }^{9}$ La encuesta de hogares del DANE de 2005 indica que Tolima, Quindío y Risaralda están entre los 4 departamentos con mayores tasas de desempleo en Colombia.

http://190.25.231.242/cgibin/RpWebEngine.exe/PortalAction?\&MODE=MAIN\&BASE=CG2005BASICO\&MAIN=WebSer verMain.inl
} 
dependen en mayor grado de otras zonas de servicios especializados (salud, educación, protección social), en especial en áreas rurales y en localidades ubicadas en zonas de ladera, donde además es insuficiente la dotación de infraestructura básica.

Las tradicionales labores de apoyo social de los Comités de Cafeteros cada vez tienen menos presencia, aunque debe admitirse que gran parte de la infraestructura social y de servicios en la región se obtuvo merced a la cofinanciación del Fondo Nacional del Café.

\section{Elementos ambientales}

En estos 92 municipios se cuenta con una riqueza hídrica conformada por los nacimientos de agua en la ladera oriental de la cordillera Occidental y en ambas laderas de la cordillera Central. Los tramos de los ríos Cauca y Magdalena son articuladores inequívocos de este proceso regional. Suman 111 las microcuencas abastecedoras de acueductos municipales.

La calidad de los suelos que caracteriza esta zona puede definirse como de alta aptitud agrologica, al tiempo que se cuenta con una diversidad de relieve y de clima. Se comparten los ecosistemas cafetero y del Chocó biogeográfico.

Como ya se ha mencionado, se dispone de importantes ecosistemas naturales, como son el Parque Natural de los Nevados, páramos, humedales y bosques en las cuencas hidrográficas que permiten la regulación hídrica. Existen aguas subterráneas como recurso alternativo que actualmente es utilizado en baja escala por particulares y poblaciones en municipios como Cartago o La Tebaida. No obstante, se presentan altos índices de contaminación de las fuentes superficiales por desechos sólidos y líquidos. Para la mayoría de los municipios existe un déficit de infraestructura en todos los niveles, tanto para el abastecimiento y potabilización del agua, como para el manejo de aguas residuales, tales como plantas de tratamiento y sistemas de acueducto y alcantarillado en áreas urbanas y rurales.

La sostenibilidad del recurso hídrico se verá comprometida en el largo plazo si se continúa con el proceso de fragmentación, deterioro y pérdida de biodiversidad en de los ecosistemas, a través de actividades económicas que conllevan deforestación en áreas de importancia ecológica. Se estima que en 2015 no menos de la mitad de los municipios de esta Ecorregión soportarán los efectos de la escasez hídrica en tiempo seco y no se vislumbran efectivas acciones preventivas.

\section{La conectividad}

Puede afirmarse que el sistema vial y de transporte de la mayoría de estos municipios, empieza a dar respuesta satisfactoria a parte de las necesidades económicas y sociales de la población. Las dobles calzadas Armenia-Manizales y Manizales-Tuluá; los probables acuerdos para conformar una Sociedad Aeroportuaria entre las terminales de Cartago y Pereira; la reactivación de la red férrea para conectar Zarzal con La Virginia, lo mismo que las opciones de la navegabilidad fluvial por el río Cauca, son hechos que advierten de una potencialidad importante. Según los informes oficiales del Ministerio de Transporte, el túnel de prueba en La Línea avanza a ritmo satisfactorio.

A pesar de los significativos avances en el sistema vial y de transporte, las articulaciones entre los municipios cordilleranos aún presentan visibles falencias y los proyectos de conexión reposan durante años en las respectivas oficinas estatales. La conectividad oriente-occidente sigue siendo un asunto por resolver en el ordenamiento territorial de esta Ecorregión. 
En cuanto a los aspectos relacionados con el acceso a fibra óptica, banda ancha y gas domiciliario, las ciudades capitales, cuentan con una ampliación de la cobertura cada vez mayor. Asimismo, los servicios de telecomunicaciones presentan mayores desarrollos tecnológicos. La infraestructura, la cobertura y la calidad del servicio de energía eléctrica, si bien depende cada vez más de agentes externos a la región, produce cada vez mejores indicadores.

Por supuesto, existen limitaciones. Por ejemplo, en la mayoría de las localidades no se dispone de rellenos sanitarios adecuados, y en algunos casos la disposición final de residuos sólidos aún se hace sobre ríos y quebradas.

Las distancias entre los municipios y sus respectivas ciudades capitales son relativamente cortas, si se las compara con otras regiones del país. Entre los puntos extremos del territorio no existe una distancia superior a los $200 \mathrm{Km}$, pero es igualmente claro que en la gran mayoría de los casos, las distancias no superan los $30 \mathrm{~km}$ y que los nuevos sistemas viales han acortado significativamente el tiempo promedio de los recorridos. Esta última circunstancia coadyuva para el aceleramiento de los procesos de metropolización ya descritos.

\section{Finanzas públicas}

\subsection{Categorización}

Según los indicadores de sus finanzas públicas, el Valle está en categoría 1, los departamentos de Caldas, Risaralda y Tolima están en categoría 2 y Quindío se ubica en categoría $3^{10}$.

Estos Departamentos han realizado importantes esfuerzos dirigidos a conseguir mejores desempeños en el indicador del endeudamiento y atender puntualmente las indicaciones contenidas en la Ley 617 de 2000 . Por ejemplo, en casos como el de Risaralda ${ }^{11}$ se consiguió pasar de una deuda superior a $\$ 50$ mil millones de pesos en 2000 a una de solo $\$ 2.200$ millones en diciembre de 2006.

Por municipios, en primera categoría están Ibagué, Pereira y Manizales; en segunda categoría se encuentran Armenia, Cartago, Dosquebradas ${ }^{12}$ y Tuluá; Villamaría y La Virginia ${ }^{13}$ están en la cuarta; Aguadas, Chinchiná, La Dorada, Riosucio, Risaralda, Calarcá, Santa Rosa y Zarzal están en la quinta categoría. Todos los demás municipios están en sexta categoría y no es claro cómo puedan ascender en este escalafón, pues se trata de un resultado al que sólo se llegará con un cumplimiento estricto de la Ley 617, pero, sobre todo, consiguiendo una

\footnotetext{
${ }^{10}$ Según el artículo 1 de la Ley 617 de 2000, los departamentos en Colombia se categorizaran presupuestalmente de la siguiente forma: Categoría especial. Todos aquellos departamentos con población superior a dos millones (2.000.000) de habitantes y cuyos ingresos corrientes de libre destinación anuales sean superiores a seiscientos mil (600.000) salarios mínimos legales mensuales. Primera categoría. Todos aquellos departamentos con población comprendida entre setecientos mil uno (700.001) habitantes y dos millones (2.000.000) de habitantes, cuyos ingresos corrientes de libre destinación anuales igualen o superen ciento setenta mil uno (170.001) salarios mínimos legales mensuales y hasta seiscientos mil $(600.000)$ salarios mínimos legales mensuales. Segunda categoría. Todos aquellos departamentos con población comprendida entre trescientos noventa mil uno (390.001) y setecientos mil (700.000) habitantes y cuyos ingresos corrientes de libre destinación anuales sean iguales o superiores a ciento veintidós mil uno (122.001) y hasta de ciento setenta mil (170.000) salarios mínimos legales mensuales. Tercera categoría. Todos aquellos departamentos con población comprendida entre cien mil uno (100.001) y trescientos noventa mil (390.000) habitantes y cuyos recursos corrientes de libre destinación anuales sean superiores a sesenta mil uno (60.001) y hasta de ciento veintidós mil (122.000) salarios mínimos legales mensuales. Cuarta categoría. Todos aquellos departamentos con población igual o inferior a cien mil (100.000) habitantes y cuyos ingresos corrientes de libre destinación anuales sean iguales o inferiores a sesenta mil (60.000) salarios mínimos legales mensuales.

${ }^{11}$ Entrevista con Jairo Ordilio Torres. Secretario de Planeación Departamental de Risaralda, 4 de diciembre de 2006.

12 Dada su vinculación al Área Metropolitana Centro Occidente (AMCO).

${ }^{13}$ Aunque ni la población ni sus recursos le permitirían estar en esta categoría, su participación en el AMCO también lo hace posible.
} 
reactivación del aparato productivo regional que le permita a las entidades territoriales obtener realmente una mayor cantidad de recursos propios.

Para casi todos los municipios, el Sistema General de Participaciones SGP sigue siendo la fuente principal de recursos, razón que explica su efectiva preocupación por el proyecto que reforma la Ley 617, en donde se busca que las entidades territoriales (municipios y departamentos, entre otros) sean más autosuficientes fiscalmente, obligándolas a generar mayores recursos propios para su funcionamiento.

Contra la hipótesis de la pereza fiscal, el esfuerzo fiscal (esto es, la capacidad de generar recursos propios), se aumentó en casi todos los municipios. Este incremento ha dependido principalmente de la actualización de los catastros y de una mejor capacidad del recaudo.

También es evidente una tendencia a disminuir el peso específico de los gastos de funcionamiento en beneficio de las inversiones y del gasto social municipal como está previsto en la Ley 617. Ahora el $61 \%$ del promedio de los gastos son para inversión.

De esta manera, en la Ecorregión los mayores desempeños están, como norma, en los municipios de mayor tamaño, y en los demás, las tareas a emprender son de gran magnitud.

En todo caso, subir de categoría es un resultado al que sólo se llegará con un cumplimiento estricto de Ley, pero, sobre todo, consiguiendo una reactivación del aparato productivo regional que permita a los departamentos y municipios obtener realmente una mayor cantidad de recursos propios.

\subsection{Las transferencias: términos de la discusión}

Está abierto el debate público alrededor de la Ley 1176 de 2007 (que modifica la Ley 715 de 2001 del Sistema General de Participaciones SGP), que se relaciona directamente con los porcentajes de las transferencias a las entidades territoriales, y que, a juicio de diferentes observadores, lesionará seriamente las finanzas territoriales, ya que desagrega la participación de propósito general y asigna tan solo un $5,4 \%$ de transferencia para el sector de agua potable y saneamiento básico ${ }^{14}$.

En su XLV Asamblea, en noviembre de 2006, la Federación de Departamentos aprobó por unanimidad una proposición que expresa un "rotundo rechazo y oposición al acto legislativo 011 de 2006 que permite cercenar de manera grave los recursos que financian la salud la educación y el agua potable a través del sistema general de participaciones (transferencias), lo cual constituye un atentado contra la descentralización y la autonomía regional". En nuestro concepto el crecimiento de las transferencias debe comportarse según los ingresos corrientes de la Nación, tal y como lo ordenó la asamblea nacional constituyente de 1991.

No es cierto, de ninguna manera, que financiar la salud y la educación, cause el colapso de las finanzas públicas. Lo que debe hacer es un verdadero ordenamiento de las prioridades y más disciplina fiscal por parte del ejecutivo central, que es precisamente donde radica la causa principal del déficit del Gobierno Nacional.

Por otra parte, prácticamente todos los municipios del Eje Cafetero disponen de su marco fiscal de mediano plazo, pero este instrumento puede resultar inocuo, si todo el escenario de las transferencias esperadas se modifica a partir de 2009, en detrimento de las finanzas públicas

\footnotetext{
${ }^{14}$ Según Jairo Ordilio Torres, Secretario de Planeación de Risaralda, este departamento y sus municipios dejarían de percibir no menos de $\$ 70$ mil millones anuales a partir de 2009, como consecuencia de las disposiciones de la Ley 1176 de 2007.
} 
territoriales como consecuencia de la disminución esperada de los recursos a transferir por el Gobierno nacional.

En todo caso, es importante que la atención gubernamental y de los partidos políticos se oriente hacia el aumento de la inversión social territorial, lo cual supone una decisión política para que en los programas de gobierno de alcaldías y gobernaciones en 2007 esta sea una prioridad.

\section{Entramado institucional y político administrativo}

La Eco-región posee una estructura político-administrativa donde coexisten municipios, resguardos indígenas, territorios de comunidades negras, comunas y corregimientos ${ }^{15}$, con dos asociaciones de municipios, una en Caldas alrededor de Supía y otra en los municipios cordilleranos del Quindío. De los tres procesos metropolitanos citados, sólo en el caso de Pereira-Dosquebradas-La Virginia se dispone de una Área Metropolitana formalmente constituida.

La descentralización al interior de las ciudades ha avanzado a ritmo lento e irregular. Aunque hay Juntas Administradoras Locales en siete de ellas ${ }^{16}$, el proceso aún no hace de las comunas y corregimientos unidades básicas de la planeación local y permanecen superpuestos los planes sectoriales de prestación de servicios.

Se tienen 38 resguardos y 5 asentamientos de comunidades indígenas, con sus respectivos Cabildos y Gobernadores, y una población que según el censo 2005 suma 85 mil habitantes; al tiempo que se cuenta con un territorio colectivo de comunidades negras con un núcleo importante en el corregimiento de Santa Cecilia, Risaralda y una colonia en dinámico crecimiento en Pereira. Según el censo 2005 la población afrocolombiana contabiliza 90 mil habitantes y se organiza, en gran medida, a través de la Consultiva de Comunidades.

Las cinco Corporaciones Autónomas Regionales ${ }^{17}$ han estructurado, entre otros acuerdos de trabajo conjunto, un importante convenio intercorporativo para trabajar alrededor de proyectos ambientales de interés común.

La gestión social aún tiene una inestable institucionalidad y no alcanza a transformarse en una estrategia dentro de las instituciones estatales, partidistas y demás organizaciones de la sociedad civil. Los acuerdos supradepartamentales en esta materia aún brillan por su ausencia.

La dimensión institucional del proceso político electoral, es un componente clave de cualquier esfuerzo de gobernabilidad democrática. En el 2003, por diferentes causas, dejaron de realizarse elecciones para Alcalde en 12 municipios de la Ecorregión. En virtud de la reforma política, ahora los períodos son institucionales y a partir de 2007 no volverá a suceder esta circunstancia.

En el año 2003 la participación electoral tuvo un promedio de 52\% para gobernaciones y 56\% para alcaldías. Participaron electoralmente prácticamente todos los partidos con personería jurídica. Los de mayor nivel de votación fueron, en su orden, el Partido de la U, el Partido

\footnotetext{
15 Las divisiones político administrativas de la Ecorregión eje Cafetero, van desde las entidades territoriales (contempladas en la Constitución Política de 1991, artículo 286) como municipios y resguardos indígenas, hasta las divisiones internas a nivel urbano (comunas) y divisiones internas de las áreas rurales municipales (corregimientos).

${ }_{17}^{16}$ Armenia, Ibagué, Manizales, Pereira, Dosquebradas, Santa Rosa de Cabal, Belén de Umbría.

17 Corporación Autónoma Regional de Risaralda CARDER, Corporación Autónoma regional del Quindío CRQ, Corporación Valle del Cauca CVC, Corporación Autónoma Regional de Caldas Corpocaldas y Corporación Autónoma Regional del Tolima Cortolima.
} 
Liberal, el Partido Conservador, Cambio Radical, Movimiento Independiente de Renovación Absoluta MIRA y el Polo Democrático Alternativo PDA.

Con desiguales procedimientos, intencionalidades y resultados se vienen desarrollando desde 2003 diversas experiencias de presupuesto participativo (Agencia Alemana de Cooperación GTZ, 2004), en las que se tiene como denominador común, el de colocar en discusión pública una porción cada vez más baja de los recursos propios de cada entidad territorial.

En los años recientes ha crecido de manera importante la institucionalidad supradepartamental tanto en el sector público, como en el privado. Esta nueva dinámica se expresa con diferentes arreglos y cubre la vida gremial (Asoeje ${ }^{18}$ ), ambiental (Convenio entre las cinco CAR citadas), de servicios (Cámara Regional de Turismo), académica (Alma Mater) o de planificación (Mesa Regional de Planificación y Comité de Eco-región). En materia de la planificación supradepartamental se dispone de la Agenda para el desarrollo sostenible de la Eco-región eje Cafetero, un instrumento para avanzar en la concertación de los acuerdos interinstitucionales y del Estado con la sociedad civil.

Estos procesos confirman la importancia de la integración regional más allá de los límites político-administrativos, para atender la solución de problemas comunes y concertar agendas colectivas de desarrollo.

Parte importante del aporte de las universidades públicas del Eje Cafetero al futuro ordenamiento territorial, es haberse agrupado y trabajar en red para construir región académica y, desde allí, aportar a la construcción de la Nación. Al reunir las 10 instituciones públicas de educación superior ${ }^{19}$ que operan en este territorio, uno de los esfuerzos ha sido contribuir a demostrar la viabilidad y las virtudes de acuerdos interinstitucionales, asentados en una nueva noción de territorio no limitado a jurisdicciones que parecían inflexibles.

En fin, desde 2000 los 92 municipios tienen aprobado su respectivo Plan de Ordenamiento Territorial $^{20}$, e incluso ciudades como Pereira (Primera Revisión POT Pereira, 2003), ya han realizado su primera revisión y ciudades como Armenia, Manizales, Dosquebradas e Ibagué están adelantando los estudios de rigor para aprobar los primeros ajustes ordenados por la Ley 388.

\subsection{Institucionalidad cafetera}

Mención aparte debe hacerse de la institucionalidad cafetera. Esta Eco-región resultaría incomprensible, sin atender el rol desarrollado en la economía regional y nacional, de la red de instituciones gremiales relacionadas con la economía cafetera, siendo el Comité Nacional de la Federación de Cafeteros, la organización con mayor presencia territorial.

No se ha agotado aún, aquel modelo en el que la Federación de Cafeteros era un Estado dentro del Estado, pero es claro que ya están superadas las condiciones históricas que lo hicieron viable y se requieren acuerdos interinstitucionales que garanticen, simultáneamente, cumplir los programas económico-sociales determinados por el Congreso Cafetero y participar, como un importante actor, de los nuevos pactos por el desarrollo regional (Pizano, 2001).

\footnotetext{
${ }^{18}$ Asociación que agrupa las Cámaras de Comercio de La Dorada, Manizales, Chinchiná, Santa Rosa de Cabal, Dosquebradas, Pereira, Cartago y Armenia.

${ }^{19}$ A saber universidades: de Caldas, Nacional -sede Manizales-; del Valle -sede Cartago-; del Quindío; del Tolima; Tecnológica de Pereira; lo mismo que la Universidad Nacional Abierta y a Distancia UNAD, la Escuela Superior de Administración Pública ESAP, la Unidad Central del Valle del Cauca UCEVA y el Colegio Integrado Nacional Oriente de Caldas CINOC.

${ }^{20}$ Cabe recordar que los 28 municipios afectados por el terremoto de 1999 estuvieron entre los primeros del país en disponer de su POT gracias, entre otros factores, al apoyo del Fondo para la Reconstrucción del Eje Cafetero FOREC.
} 
La presencia institucional, en la mayoría de las zonas rurales, se ha restringido en la misma medida en que las inversiones tradicionales de los Comités de Cafeteros, han ido desapareciendo sin que los gobiernos territoriales puedan reemplazarlas como fuente de financiación. La deuda social con los asalariados y campesinos pobres sigue vigente y debe pagarse cuanto antes.

El café trasciende lo regional y se torna en un tema de alcance nacional puesto que su futuro incidirá en la estabilidad democrática del país. Por ello, la red social cafetera debe ser una prioridad en la política pública colombiana.

\section{Financiación del desarrollo regional}

En esta Eco-región se cuenta con una institucionalidad que sirve de soporte para financiar el desarrollo socio económico. Entre ellas se destacan el Instituto de Financiamiento, Promoción y Desarrollo de Caldas Inficaldas, el Instituto de Financiamiento, Promoción y Desarrollo de Manizales Infimanizales ${ }^{21}$ (que son bancos de inversión propiamente dichos), el Instituto Financiero para el Desarrollo de Risaralda Infider y el Instituto Financiero para el Desarrollo del Quindío Indequi. Los desarrollos y el mandato general de la Ley 715 de 2001 representan una importante oportunidad para participar en la administración de los recursos del SGP ${ }^{22}$.

El Fondo de Regalías ha significado una importante fuente de recursos para financiar obras relacionadas con saneamiento básico y agua potable, y será necesario estar atentos a las reformas legales que el alto gobierno espera introducir en este instrumento. Asimismo, la experiencia regional con la Financiera para el Desarrollo Territorial Findeter indica que se ha mantenido un sistema de créditos que atiende esencialmente a las ciudades de mayor tamaño y obliga a los demás municipios a buscar fuentes alternas de financiación de sus proyectos.

Pero, aún si se diera vía libre a esta alternativa, la financiación del desarrollo para la Región no estaría sino parcialmente resuelta y sería indispensable que otros mecanismos y opciones se aplicaran. Cabrían en este sentido estudios específicos sobre el rol que han cumplido en estos municipios el Fondo de Solidaridad y Garantías, el Fondo Nacional de Garantías, el Fondo para el Desarrollo de la Micro, la Pequeña y la Mediana Empresa, lo mismo que el Instituto para el Financiamiento Industrial y los demás Fondos estatales.

De manera complementaria se cita lo que pueda suceder regionalmente con el Banco de los Pobres y el programa de crédito con garantía automática, dirigido a microempresas en una alianza de la cual hacen parte el Fondo Nacional de Garantías, las respectivas entidades territoriales y las entidades financieras seleccionadas.

\section{Capital social}

En el Eje Cafetero se dispone de una muy baja participación en organizaciones horizontales, orientadas a la búsqueda del bienestar colectivo, pues sólo en $14 \%$ de los hogares, al menos uno de sus miembros participa en organizaciones comunales, religiosas o políticas, mientras que en el país la cifra es del $45 \%$. Además, solo el $30 \%$ de la población rural y el $28 \%$ de la

\footnotetext{
${ }^{21}$ Estas dos entidades se han convertido en importantes apalancadoras de obras de infraestructura. En ellas se apoya, por ejemplo, la cofinanciación del Aeropuerto de Palestina.

${ }^{22}$ Según el periódico La Tarde, 4 de diciembre de 2006, así se defiende en un proyecto de Ley que hace curso en el Congreso.
} 
población urbana, participa en las juntas de acción comunal de sus barrios (PNUD, 2004). El nivel de intervención en elecciones no partidistas es bajo, para las elecciones gremiales sólo participa el $14 \%$ y en las elecciones cafeteras lo hace el $24 \%$.

Sin embargo, en el campo gremial se ha ido generando un importante trabajo en red que se expresa en Asoeje, y que se ha creado una oficina regional de la Asociación Colombiana de Pequeños Industriales ACOPI, que ahora agrupa a Quindío, Risaralda y norte del Valle. Recientemente se ha conformado una Red Regional de Seguridad Alimentaria que congrega productores, académicos y funcionarios públicos. Los productores de guadua se han asociado y ahora trabajan mediante un acuerdo de competitividad que tiene el aval de las autoridades ambientales.

La Sociedad Promotora Arquímedes, una institución mixta que cuenta con el aporte de gobernaciones (Caldas, Risaralda, Chocó), 8 Alcaldías, 3 instituciones de educación superior y Alma Mater, 5 Cámaras de Comercio, además de Asoeje, la Sociedad Puerto de Tribugá y otros representantes del sector privado, se erige como un claro argumento a favor de acuerdos interinstitucionales y supradepartamentales para conseguir intereses colectivos. En este caso, los relacionados con la vía Animas-Nuquí y con el puerto de Tribugá. Esta Sociedad resume bien un esfuerzo de agrupación de voluntades y de formación de capital social regional.

El convenio Universidad-Empresa-Estado construyen región ${ }^{23}$, suscrito en 2007, es otra muestra de progreso en la construcción de capital social proclive a acuerdos en beneficio del desarrollo regional.

\section{Conflicto armado}

Este territorio no es ajeno al conflicto armado ni a la actividad propia de los narcotraficantes y de grupos guerrilleros y paramilitares. Como en el resto del país, las expresiones del conflicto armado han disminuido, pero no han desaparecido. Según Acción Social entre 1994 y octubre de 2006 sumaron 57 mil las personas expulsadas por el conflicto armado y 19 mil las personas que llegaron a Caldas, Quindío y Risaralda. En estos departamentos se recibe el $4 \%$ de los expulsados y se expulsa el $3 \%$ del total nacional. Además la población campesina, indígena y afrocolombiana ha sufrido el despojo de sus tierras, ha sido víctima de asesinatos selectivos, amenazas y otras formas de intimidación, lo cual hace que la gobernabilidad democrática haya padecido serios traumatismos.

Grupos guerrilleros, especialmente las FARC y el ELN ${ }^{24}$, realizaron algunas acciones armadas y secuestros en 2006, al tiempo que se produjeron serios golpes militares al reducto del EPL en el territorio de Caldas y Risaralda. Por otra parte, el asesinato de Liliana Gaviria, hermana del expresidente César Gaviria, y diferentes secuestros mantienen enrarecido el ambiente por la presencia de grupos paramilitares y comandos guerrilleros ${ }^{25}$.

\footnotetext{
${ }^{23}$ Según Palacio (2007), para establecer la conexión entre Universidad-Empresa-Estado, "se propone, desde la ciudadanía como un proceso de práctica social orientada hacia el ejercicio permanente del reconocimiento. De la inclusión como agentes en ejercicio y goce de derechos, acceso equitativo a las oportunidades y formación de sus potencialidades. Recuperado 20 de marzo, 2008, de

http://www.almamater.edu.co/new_page/documento/memorias_foro_itinerante/Memorias/3_Ponencias/4_MANIZALES/ 3_UEE.Un.Entrelazamiento.desde.la.Ciudadania_Mar\%C3\%AD̄a.Cristina.Palacio.pdf.

${ }^{24}$ Convenio del cual hacen parte instituciones académicas de educación superior, Cámaras de Comercio, la Asociación Nacional de Industriales ANDI y el PNUD.

${ }^{25}$ Dadas sus evidentes connotaciones políticas, el episodio de la señora Gaviria, además de otros efectos, causó la renuncia del general Mario Gutiérrez como responsable de la Policía en la jurisdicción que cubre Caldas, Quindío, Risaralda y norte del Valle.
} 
En la región se realizaron en 2006 dos desmovilizaciones de estructuras paramilitares: una en Santuario (Risaralda), bajo el mando de Carlos Mario Jiménez Naranjo alias Macaco, con 550 personas y otra en La Dorada y Puerto Salgar, donde Ramón Isaza encabezó la desmovilización de 850 personas. En el oriente de Caldas se mantiene armada una estructura paramilitar denominada cacique Pipintá.

A propósito, la prensa local informa que, en el caso de Santuario y del oriente de Caldas, el retorno de los paramilitares es una realidad y que ha vuelto igualmente la zozobra y la inseguridad. Información que, sumada a las dificultades propias de la aplicación de la Ley de verdad, justicia y reparación, devela la complejidad de este proceso y llama la atención sobre los eventuales impactos acerca del futuro de la estabilidad institucional.

En cuanto a la violencia social, en 2005 (año de expedición de la Ley $975^{26}$ ) la tasa de homicidios por cada cien mil habitantes fue de 89 en Risaralda, 42 en Caldas y 22 en Quindío, mientras que a nivel nacional dicho indicador fue de 47. Por supuesto, preocupa la creciente presencia de pandillas y bandas juveniles, y su capacidad para afectar la vida y demás derechos fundamentales en ciudades como: Pereira, Dosquebradas, Ibagué y Manizales. Algunos observadores sostienen que este fenómeno está explicado, en gran medida, en la coyuntura por la participación en esos grupos por parte de jóvenes desmovilizados y por la decisión de las FARC de conseguir presencia urbana.

Debe estimularse el debate público a propósito de: ¿Cómo aportar, desde la región, al necesario acuerdo humanitario?, ¿Cómo garantizar que la ley de justicia y paz efectivamente conduzca a nuevas opciones de convivencia pacífica?, ¿Cómo fortalecer las instancias de mediación, los jueces de paz y procesos similares?, ¿Qué podemos y debemos hacer desde la Ecorregión para que las eventuales negociaciones de paz con las FARC y con el ELN se transformen en una realidad?, y ¿Qué iniciativas específicas desde la sociedad civil pueden valorarse y replicarse como buenas prácticas para la paz?.

\section{Las agendas para el desarrollo regional}

Las autoridades nacionales de planeación admiten la importancia de "promover dinámicas territoriales que trasciendan los límites político administrativos" y la apuesta a que en 2010 el país "deberá haber ajustado el marco constitucional y aprobado la ley orgánica que permita un ordenamiento flexible, con nuevas formas de organización e integración" (DNP, 2005, pág. 325).

Cada día es más claro que gran parte de las dificultades de esta Ecorregión no se pueden resolver en el marco de las actuales fronteras los departamentos que la integran. Por consiguiente, es indispensable flexibilizar los arreglos institucionales y desarrollar una gestión pública que facilite los entendimientos con el norte del Valle y el noroccidente del Tolima.

La Agenda Interna Nacional no puede ser entendida como la sumatoria de agendas construidas en los límites departamentales. Se requieren acuerdos auténticamente regionales que faciliten la perspectiva de la productividad y la competitividad, por una parte, y el desarrollo social, por la otra, como dos de las dimensiones esenciales del país en su ruta hacia el 2019.

En este territorio se dispone de un amplio abanico de Agendas y Planes que son necesarios concertar. Desde las agendas internas y de competitividad, pasando por los planes departamentales y municipales de desarrollo y los planes estratégicos de gestión ambiental

\footnotetext{
${ }^{26}$ La Ley 975 de 2005, dicta las disposiciones para la reincorporación de miembros de grupos armados organizados al margen de la ley, que contribuyan de manera efectiva a la consecución de la paz nacional.
} 
regional, hasta la Agenda para el Desarrollo Sostenible del Eje Cafetero y el propio Pacto por la Región, conforman un nutrido conjunto de iniciativas que deben articularse de la mejor manera posible.

En la coyuntura se enfrenta un desafío de doble dimensión: a) Como tal, la Agenda concertada debe servir de instrumento para movilizar social y políticamente la población, en pro de los objetivos allí consignados; b) Se debe dotar a este territorio de una Agenda Regional de Ciencia, Tecnología e Innovación.

Adicionalmente, desde el 2001, se cuenta con un convenio entre las cinco Corporaciones Autónomas Regionales con asiento en la Ecorregión, y este acuerdo, aún por encima de las dificultades que se puedan observar en el manejo puntual de algunos temas, indica que sí es posible un manejo interinstitucional que responda por proyectos regionales.

Ahora bien, en opinión del PNUD (2004, pág. 174), las agendas regionales carecen de algunos aspectos básicos en el tema específico del desarrollo humano y en la operatividad de las estrategias.

Para la gestión política y la concertación entre las agendas regionales de desarrollo, el Pacto por la Región promovido por el PNUD "concibe la necesidad de promover alianzas estratégicas entre los diferentes actores regionales para acometer los grandes proyectos de desarrollo en la región. Sobre la base de la premisa anterior, el Pacto acoge las líneas de acción y programas o proyectos de Ecorregión orientados a incidir en la sostenibilidad del Eje Cafetero" (2004, pág.173).

Además, parece existir consenso en la necesidad de priorizar en las agendas púbicas la lucha contra la pobreza. En esta dirección es indispensable refundar el Pacto suscrito en 2003 para transformar las Metas y Objetivos del Milenio, en la principal agenda social de las administraciones municipales y seccionales del Eje Cafetero.

Conviene entonces proceder a tejer nuevas y más potentes relaciones regionales entre las oficinas departamentales de Acción Social, las demás entidades nacionales que se relacionan más directamente con el quehacer de aquellas (Servicio Nacional de Aprendizaje SENA, Instituto Colombiano de Bienestar Familiar ICBF, Ministerio de Protección Social, Ministerio de Agricultura) y la propia institucionalidad local y departamental. Pero es igualmente indispensable generar y fortalecer capacidad institucional para disponer de adecuadas líneas de base y de sistemas de seguimiento y control, que permitan evaluar la dinámica de cumplimiento de cada una de las metas del milenio en los diferentes municipios.

El cumplimiento de las Metas citadas pasa por una redefinición institucional. La Mesa Regional de Planificación que por ahora agrupa a las Secretarías de Planeación de Caldas, Quindío y Risaralda, y a sus pares de las tres ciudades capitales, debería sumar a voceros del norte del Valle y del noroccidente del Tolima, de tal manera que se atiendan los requerimientos de desarrollo de la Ecorregión Eje Cafetero en su conjunto. En este sentido, la propia institucionalidad territorial del PNUD debería flexibilizarse para tener en cuenta las necesidades de una región que tiene una compleja jurisdicción territorial.

De igual manera, es fundamental fortalecer la capacidad institucional de las alcaldías de menores recursos para dotarlas, al menos, de los paquetes tecnológicos que les permitan acopiar, sistematizar y evaluar a escala urbano-rural la información relacionada con las variables e indicadores que integran las Metas del Milenio.

Mientras se analizan en detalle los datos oficiales del censo 2005, y se contrasta con los hallazgos obtenidos en el Informe del PNUD, se deben aplicar programas prioritarios de 
carácter urgente y proyectos con focalización en los municipios de máxima prioridad ${ }^{27}$ : Filadelfia, La Dorada, Marulanda, Neira, Pensilvania, Riosucio, Risaralda, Alamina y Samaná en Caldas; La Celia, Mistrató, Pueblo Rico y Quinchía, en Risaralda, y Córdoba en Quindío. En el norte del Valle, se deben considerar los municipios que resulten con esas características en el informe preparado por el PNUD, y en el noroccidente del Tolima, incluir los municipios que a juicio de la Secretaría de Planeación merecen una atención inaplazable.

\subsection{Pacto región-Nación}

Así pues, refundar el pacto por la región debe significar un compromiso de política pública para trabajar con fundamento en los lineamientos del Informe de Desarrollo Humano, apoyarse en los Documentos CONPES 91 de 2005 y 102 de $2006^{28}$, ajustarlos a la realidad regional para avanzar progresivamente en el cumplimiento local de las Metas del Milenio y transformarlas en los propósitos prioritarios en cada uno de los municipios.

Según el PNUD (2004, pág. 219), la "armonización de las políticas, planes y programas subnacionales con los nacionales se debe dar a través de un proceso de información, participación", consiguiendo así un acuerdo o contrato entre la Nación y la Región, entendido como "un acuerdo de voluntades para la gestión y el desarrollo".

Desde el proceso de Ecorregión Eje Cafetero se trabaja en la perspectiva de desarrollar la gestión político institucional y académica, necesaria para que este acuerdo o contrato se viabilice a través de un Documento CONPES (Castaño, 2006).

\subsection{Violencia y paz}

La gestión político institucional en pro de la paz debe garantizar, en primer lugar, una presencia estatal integral y eficaz en todo el territorio. En la coyuntura, entre otros objetivos, se requiere impedir que las fuerzas paramiliatares desmovilizadas, copen por otras vías y desborden la capacidad de la institucionalidad local y departamental.

Es preciso, impedir que un proyecto estratégico como lo es la carretera Animas-Nuquí (vía al Pacífico), considerada como estratégica para el desarrollo regional, se transforme en un territorio copado por actores armados irregulares. En todo caso, no sólo se debe velar por el control militar de la vía, sino por ofrecer programas de desarrollo social para atender las comunidades asentadas en dicho territorio, y programas de sostenibilidad ambiental enmarcados dentro de las directrices ambientales, contempladas en los planes de ordenamiento territorial de los municipios involucrados.

Es indispensable una mejor preparación de las alcaldías y gobernaciones para interactuar positivamente con los actores del conflicto; consolidar los esquemas de seguridad que garanticen el control de las armas por parte del Estado; eliminar las minas anti personales; estimular la participación activa de actores locales en las redes que se han ido construyendo en Colombia desde la sociedad civil para trabajar en bien de la paz ${ }^{29}$. En todos los municipios del Eje Cafetero, debe contarse con planes de derechos humanos y fortalecerse el sistema

\footnotetext{
${ }^{27}$ Es decir, aquellos que partieron de niveles bajos (inferiores al promedio) de desarrollo humano en 1993 y que, al final del período (2002), se encontraban en una situación aún peor. Por su parte, los municipios de alta prioridad (27 en total) corresponden a los que habiendo partido de niveles elevados de desarrollo humano (superiores al promedio) experimentaron un retroceso en el indicador, a pesar de haber partido de niveles bajos.

${ }^{28}$ El Consejo Nacional de Política Económica y Social CONPES fue creado por la Ley 19 de 1958. Esta es la máxima autoridad nacional de planeación y se desempeña como organismo asesor del gobierno en todos los aspectos relacionados con el desarrollo económico y social del país. Ver http://www.dnp.gov.co/PortalWeb/tabid/55/Default.aspx ${ }^{29}$ Por ejemplo, la red que agrupa los Programas de Desarrollo y Paz PRODEPAZ, en diferentes zonas del país; la Red de iniciativas por la descentralización, la autonomía territorial y la paz; la Red de investigaciones sobre población desplazada por el conflicto armado interno, entre otras.
} 
regional de atención integral a la población desplazada, mejorando los niveles de coordinación interinstitucional entre las directrices y los recursos nacionales, regionales y locales.

Es necesario coordinar y mejorar la atención específica tanto a la población desmovilizada ${ }^{30}$, como a las víctimas del conflicto interno armado. En este sentido, deben adoptarse las decisiones institucionales indispensables, para conseguir una adecuada participación en la oficina regional de la Comisión Nacional para la Reconciliación y Reparación de las víctimas.

Es importante trabajar desde ya para el postconflicto, mediante el fortalecimiento de programas de desarrollo y paz (programas que, por supuesto, no están diseñados para sustituir la institucionalidad púbica); la intensificación de ofertas pedagógicas sobre cultura ciudadana y la ejecución de tareas y actividades propias de las movilizaciones por la paz (PNUD, 2004, pág. 218).

En estas materias la institucionalidad y la capacidad de gestión pública puede resultar fortalecida con acuerdos específicos y con agencias internacionales de cooperación. Por ejemplo, serían indispensables formas novedosas de entendimiento interinstitucional entre el PNUD, la GTZ y las entidades públicas y privadas, alrededor de propósitos comunes de convivencia pacífica y gobernabilidad democrática.

Además, conviene que avance de manera significativa la investigación y el conocimiento sobre los temas del conflicto armado interno y la paz. Construir una región del conocimiento sobre estos asuntos resulta de importancia no solo para la adopción de mejores políticas públicas, sino para atender con mayor rigor las necesidades de una pedagogía de paz.

La gestión regional por la paz también incluye, acuerdos interinstitucionales para garantizar una información pertinente en términos de calidad, cantidad, continuidad y capacidad de adaptación a las redes y sistemas nacionales e internacionales sobre el tema. Sin estos sistemas especializados de información, las iniciativas destinadas a articular los observatorios del conflicto y la convivencia resultan inviables. Para esta tarea es esencial sumar los recursos, entre otras, de las Secretarías de Gobierno, las oficinas departamentales de Acción Social y las instituciones de educación superior, lo mismo que de las ONG especializadas en el tema.

En todo caso, el país continúa esperando la aprobación de la Ley Orgánica de Ordenamiento Territorial ordenada por la Constituyente en 1991. Sin este instrumento parece imposible completar las piezas del rompecabezas para las eventuales negociaciones de paz.

Dadas las dimensiones y naturaleza del conflicto armado, el ordenamiento territorial debe ser asumido como instrumento de paz. Guardando las proporciones, esta Ley debe jugar un rol similar al que en su momento desempeñó la Constitución de 1991. Se requiere transformar este ordenamiento en un pacto ciudadano que permita contribuir a la construcción de la Nación en condiciones de convivencia pacífica y de desarrollo sostenible.

\subsection{Financiación}

Además de luchar porque el régimen de transferencias retorne a la fórmula establecida en la Constitución de 1991, la principal tarea en esta materia, está relacionada con formular y adoptar un programa estratégico de financiación del desarrollo regional que incorpore una valoración global de los programas contenidos en la Agenda, que identifique fuentes de financiación y adopte mecanismos específicos para la inversión de los recursos necesarios.

\footnotetext{
${ }^{30}$ Personas que estuvieron en los grupos paramilitares que comandaban los alias de Macaco en Santuario, Ramón Isaza en el Magdalena Medio y Ernesto Báez en el norte de Caldas. Lo mismo que los desmovilizados individuales de organizaciones guerrilleras.
} 
Se requiere que los municipios "puedan hacer un uso más libre de una proporción de los recursos transferidos, siempre y cuando logren cumplir con metas específicas en cuanto a aumento de recursos propios y mejora en cobertura, eficiencia y calidad de los servicios prestados" (PNUD, 2004, pág. 218).

Debe buscarse un escenario en el que el crecimiento de los recursos propios de las entidades territoriales, contribuya a garantizar la efectiva atención de las demandas sociales y la inversión pública local y regional.

No deberían existir cortapisas para que, llegado el caso, existan acuerdos entre los Institutos de Financiamiento y Promoción del Desarrollo INFI, para aportar a la financiación de proyectos que trasciendan los límites político-administrativos de sus respectivas jurisdicciones y contribuir a financiar proyectos de impacto regional. Esta perspectiva se encuentra, sin embargo, condicionada a la necesidad de conseguir acuerdos para vincular mucho más activamente a Pereira ${ }^{31}$ y Armenia, al sistema de financiación del desarrollo regional. Sin la participación de los recursos de estas dos ciudades capitales, difícilmente se obtendrían los mínimos de capital indispensables para atender el financiamiento de los proyectos de carácter regional.

\subsection{Otras recomendaciones}

Es indispensable recorrer la ruta del desarrollo endógeno; avanzar hacia la modernidad fortaleciendo la ciudadanía y construyendo nuevas formas de entendimiento entre la sociedad civil y el Estado, lo mismo que entre el Gobierno Central y las autoridades locales y regionales.

Se debe afianzar la presencia institucional de las alcaldías y gobernaciones en todo el territorio regional, y garantizar los derechos de las comunidades étnicas a sus territorios y formas de gobierno. Es fundamental fortalecer los proyectos de vida definidos por las autoridades y gobiernos de las comunidades indígenas, y de la población afrocolombiana con asiento en la Ecorregión.

Por otra parte, se debe avanzar en la generación de condiciones favorables para el desarrollo económico y social en todos los municipios, de tal forma que se promuevan mayores relaciones de cooperación, otorgando énfasis a los proyectos que cubren dos o más departamentos, y atendiendo las limitaciones y potencialidades de la plataforma natural.

Se sugiere entonces desplegar una gobernabilidad democrática sobre los asuntos públicos para el bienestar colectivo, con una eficiente coordinación interinstitucional, intersectorial y entre actores del desarrollo; se trata de una gran alianza de voluntades y capacidades que aborde con eficiencia las prioridades regionales, administre y ejecute estratégicamente los recursos y proyectos claves para el desarrollo regional..

Lo dicho supone escenarios para conseguir, con el apoyo de la academia, un mayor saber social, esto es, la obligación de estudiar más; de contextualizar mejor; de decantar las experiencias; de obtener, producir y divulgar más información, de consolidar la comunicación, y de fortalecer la infraestructura y el equipamiento social.

Por último, desde el punto de vista político institucional, es recomendable consolidar el trabajo de redes públicas como las expresadas en los convenios de: las Corporaciones Autónomas Regionales; de la red de universidades públicas del Eje Cafetero (Alma Mater), y del convenio Universidad-Empresa-Estado construyen Región.

\footnotetext{
${ }^{31}$ La Alcaldía de Pereira ha conformado una Promotora para el desarrollo.
} 
Fortalecer, por diferentes vías y procedimientos, la capacidad institucional de las organizaciones de la sociedad civil; su asociatividad; sus organizaciones de segundo grado y sus redes.

Potenciar la Red de Seguridad Alimentaria para la Ecorregión Eje Cafetero.

Adoptar la metodología de presupuesto participativo. Hacer realmente pública la información de fuentes y usos de recursos.

Garantizar una mayor promoción y utilización de la Ley 134 de 1994 y ofrecer incentivos locales para la participación ciudadana.

Consolidar los Consejos Territoriales de Planeación y los Consejos Territoriales de Política Social.

Fortalecer el papel subsidiario de los departamentos.

Mejorar la gestión y la institucionalidad para conseguir una mayor presencia de la cooperación internacional. Se debe vigilar que esta cooperación opere sobre la base de proyectos regionales concertados en la agenda común.

La renovación institucional busca, entre otros objetivos, enfrentar problemas de cohesión social. Este debe ser el propósito central de las políticas públicas en la región, y debe acompañarse de una incuestionable legitimidad social, condición que procede de la participación de los diferentes actores en el diseño e implementación de tales políticas.

Por supuesto, todo lo anterior pasa por reivindicar la política, como institución social para la tramitación y renovación de los intereses colectivos. Y tiene como condición el fortalecimiento de la confianza mutua entre los actores del desarrollo. Es necesario, pues, visualizar un marco institucional que abarque no sólo las formas de intervención de las agencias estatales, sino también el conjunto de reglas y convenciones no formales, e incluso incorpore normas éticas y morales de comportamiento que son parte de la interacción social.

La Ecorregión Eje Cafetero es una región en marcha, que tiene iniciativa propia, que no se ha sentado a esperar las decisiones del Gobierno Central, ni se ha limitado a hacer antesala para que lleguen los grandes acuerdos políticos que despejen completamente el camino y hagan del desarrollo regional en Colombia un escenario exento de conflictos y tensiones.

Es de esperar que para las elecciones de 2007, se produzcan diversos arreglos políticopartidistas que ayuden a conformar un mapa donde los actores se puedan diferenciar claramente unos de otros, sobre la base de sus ofertas programáticas y sea a través de ellas que se establezcan las eventuales alianzas. Exigir claridad y coherencia en las posiciones de cada Partido, sobre el desarrollo regional, es un imperativo para el futuro de la democracia y de la estabilidad institucional en Colombia.

En fin, tanto para el Pacto por la Región auspiciado por el PNUD, como para la Agenda de la Ecorregión, "el Eje Cafetero es un inmenso territorio de oportunidades, las cuales deben ser equitativamente distribuidas para que el mayor número de pobladores tenga acceso a mejores condiciones de vida, más dignas" (2004, pág.223). 


\section{BIBLIOGRAFÍA}

Castaño, Diego. Propuesta de Documento CONPES. Agenda para el desarrollo sostenible de la Ecorregión Eje Cafetero. Pereira: Universidad Tecnológica de Pereira UTP, 2006.

Castro, Jaime. La cuestión territorial. Bogotá: Oveja Negra, 2002.

Pizano, Diego. El café en la encrucijada. Evolución y perspectivas. Bogotá: Alfaomega, 2001.

Documentos técnicos consultados

Agencia Alemana de Cooperación GTZ. Presupuesto participativo. Risaralda. Experiencia metodológica y resultados. Bogotá, 2004.

Alcaldía municipal de Pereira. Plan de Ordenamiento Territorial de Pereira. Primera revisión. Pereira, 2003.

Departamento Nacional de Planeación DNP. 2019. Visión Colombia I/ centenario. Propuesta para discusión. Bogotá, 2005.

Programa de la Naciones Unidas para el Desarrollo PNUD. Un pacto por la región. Informe de desarrollo humano del Eje Cafetero. Bogotá, 2003.

Programa de la Naciones Unidas para el Desarrollo PNUD. Hacia un pacto por la región. Informe de desarrollo humano del Eje Cafetero. Bogotá, 2004.

Legislación colombiana consultada

República de Colombia, Congreso de la república. Ley 617 de 6 de octubre de 2000, por la cual se reforma parcialmente la Ley 136 de 1994, el Decreto Extraordinario 1222 de 1986, se adiciona la Ley Orgánica de Presupuesto, el Decreto 1421 de 1993, se dictan otras normas tendientes a fortalecer la descentralización, y se dictan normas para la racionalización del gasto público nacional.

República de Colombia, Congreso de la república. Ley 715 de 21 de diciembre de 2001, por la cual se dictan normas orgánicas en materia de recursos y competencias de conformidad con los artículos 151, 288, 356 y 357 (Acto Legislativo 01 de 2001) de la Constitución Política y se dictan otras disposiciones para organizar la prestación de los servicios de educación y salud, entre otros.

República de Colombia, Congreso de la república. Ley 975 de 25 de julio de 2005, por la cual se dictan disposiciones para la reincorporación de miembros de grupos armados organizados al margen de la ley, que contribuyan de manera efectiva a la consecución de la paz nacional y se dictan otras disposiciones para acuerdos humanitarios.

República de Colombia, Congreso de la república. Ley 1176 de 27 de diciembre de 2007, por la cual se desarrollan los artículos 356 y 357 de la Constitución Política y se dictan otras disposiciones.

Recursos de internet consultados

Departamento Administrativo Nacional de Estadística DANE. Sistema de Consulta REDATAM. $\begin{array}{lllll}\text { Recuperado } & 12 & \text { marzo, } & \text { de }\end{array}$ 
http://190.25.231.242/cgibin/RpWebEngine.exe/PortalAction?\&MODE=MAIN\&BASE=CG2005B ASICO\&MAIN=WebServerMain.inl

Departamento Nacional de Planeación DNP. Consejo Nacional de Política Económica y Social. Recuperado 17 marzo, 2007, de http://www.dnp.gov.co/PortalWeb/tabid/55/Default.aspx

Ministerio de Ambiente Vivienda y Desarrollo Territorial MAVDT. Criterios que definen una Ecorregión estratégica. Recuperado 23 de mayo, 2007, de http://web.minambiente.gov.co/ecorre/intro/intro3.htm.

Red de Universidades Públicas del Eje Cafetero Alma Mater. Foro Regional Sostenible con Responsabilidad Social. Recuperado 20 de marzo, 2008, de http://www.almamater.edu.co/new_page/documento/memorias_foro_itinerante/Memorias/3_Po nencias/4_MANIZALES/3_UEE.Un.Entrelazamiento.desde.la.Ciudadania_Mar\%C3\%ADa.Cristi na.Palacio.pdf. 